\title{
D-Move: A sociotechnical environment to provide experience- based learning to digital natives
}

\author{
Petrovic, Otto a and Lembeck, Martin ${ }^{\mathrm{b}}$ \\ ${ }^{a}$ Institute of Information Science and Information Systems, Karl Franzens University Graz, \\ Austria, ${ }^{\mathrm{b}}$ Institute of Information Science and Information Systems, Karl Franzens \\ University Graz, Austria
}

\begin{abstract}
Digital natives grew up in the world of digital media and live in it. They have different learning styles, call for other teaching methods, and are using different means of communication in their learning processes. In this paper the D-Move learning environment is presented and evaluated. It is a methodology as an extension of the Delphi method together with a software system to implement this methodology. It offers digital natives an experienced-based learning environment and is perceived by the learners as superior to traditional learning based on case studies with regard to activation, satisfaction with the learning process, and satisfaction with the learning environment. At the same time D-Move is used as a research environment to better understand disruptive innovations in the world of digital. The underlying assumption is that a better understanding of already existing differences between digital natives and their parent generation will bring insights into future large scale transformation processes. The main two components of D-Move are a module to support Delphi studies with online and offline components as well as a module to capture, annotate and structure real world experiences to support the Delphi contributions.
\end{abstract}

Keywords: Field learning; ethnographic studies; case study learning; Delphi study, experience-based learning, digital natives. 


\section{Introduction - Aims of D-Move, the proposed experienced-based learning environment}

D-Move pursue two main aims: Firstly, digital natives ask for different learning environments and use different means of communication in their daily life. Secondly, $D$ Move should help at the same time to gain insights into disruptive innovations in the world of digital and in future large scale transformations based on them. Thus, the benefit of $D$ Move is to have a software system and a methodology based on the Delphi method considering and exploiting the changed communication behavior of Digital natives.

Digital media is an essential component for the communication of digital natives (Thompson, 2013); (Friedl \& Verčič, 2011). This change in the social and technological behavior has a major impact on the learning and information seeking environments of young students (Purcell et al., 2012). In times of increasing information sources, the uncertainties about the authenticity of content grows and students need a proof for them (Purcell et al., 2012). So information based on self-developed knowledge within real-life experiences become more important (Kong et al., 2014). As a consequence, digital natives call for different sociotechnical learning environments.

The first aim of D-Move, the experienced-based learning environment proposed and evaluate in this paper, is to fulfill those new requirements of learners better than traditional classroom teaching based on case studies.

Traditional expert-based trend research encounters noteworthy difficulties in dealing with disruptive innovations. Those are mainly characterized by generating new markets and changing existing ones radically. As a consequence they have a high social impact. Examples of this are the mass production in the automotive industry or the strong spread of smartphones. The driving force of disruptive innovations are usually not existing market leaders because these allocate their resources on hitherto successful business models based on traditional ways of thinking. Digital natives are characterized by the fact that they grew up in the world of digital and live in it. They are not immigrant into this world like digital immigrants or have to approach the world of digital mainly by use of scientific methods. When using digital immigrants as experts in trend research there is a danger that thinking based on incremental innovations leads to the optimization of existing business models but not to the development of new ones.

The basic assumption of D-Move is, that digital natives are trendsetters for as well as early adopters of disruptive innovations in the world of digital. Thus, the main aim is to understand their current behavior as an indicator for future large scale transformation processes. D-Move is mainly used as a sensor into the current behavior of digital natives to find future large scale transformations and not primary as a platform to collect expert opinions on future developments. Within the D-Move learning environment digital natives 
are therefore considered to be experts about transformation processes already taking place. To implement this modified Delphi method they are supported by the Review board, which brings comprehensive knowledge of methods into the process.

The second aim of D-Move is to act as a research environment to gain insights into disruptive innovations in the world of digital and in future large scale transformations based on them.

\section{Elements and characteristics of the D-Move learning environment}

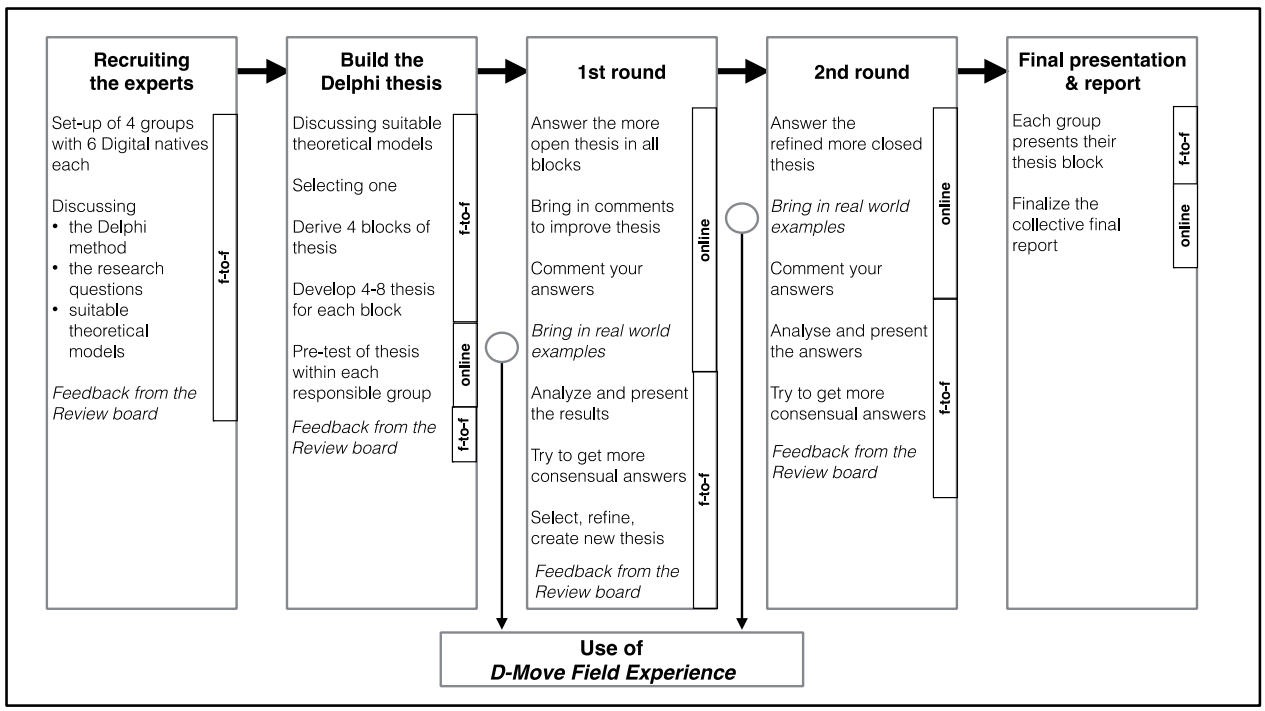

Figure. 1 Implementation of D-Move Delphi as part of an experience-based learning environment

The implementation of the D-Move Delphi learning environment offers four main characteristics: support of experienced-based learning, facilitation of interaction with peers, usage of familiar means of communication, an give learners the role of experts. To fulfill those four goals a modified Delphi method is implemented with face-to-face as well as asynchronous-dispersed forms of communication. The first goal, enable experienced-based learning, should be reached by two characteristics of D-Move. Firstly, the students are actively engaged in the learning domains by their role as participants in the Delphi instead of being in a traditional classroom situation. Secondly, by using real world experiences to explain their positions supported by the Field Experience Module of the D-Move learning environment experienced-based learning is further facilitated. The second goal, the interaction with peers, is supported by strong interaction with other digital natives in the Delphi group, e.g. in discussing the research questions, building the Delphi thesis, trying to get more consensual answers, and preparing the final report jointly. The third goal, use of 
familiar forms of communication, is fulfilled by using online questionnaires to answer the Delphi thesis and shared digital spaces to communicate and share documents within and between the groups as well as to interact with the Review board. The use of the D-Move Field Experience Software further supports this goal by functions like capturing and posting videos, pictures and textual description from their smartphones directly to domain specific video blogs in a structural form.

The fourth goal, learners become the role of experts, is fulfilled by engage them within the Delphi as experts for the Delphi thesis. Thus, they can bring in their real world expertise as digital natives to improve the quality of the Delphi outcomes dealing mainly with disruptive innovations as described above. Secondly, the engagement will improve the motivation of the students, as their expertise is really needed in contrast to traditional learning forms based on case studies.

As Fig. 1 shows, the D-Move Delphi consists of five main components. In each one the students act as the experts for the content of the Delphi thesis and the Review board, faculty members responsible for the course, supports them with methodological advice. Components 2 to 5 have face-to-face as well as online elements and the 1st and 2nd Delphi round is using a direct link to the D-Move Field Experience Software to support the positions regarding the Delphi thesis with real world experiences.
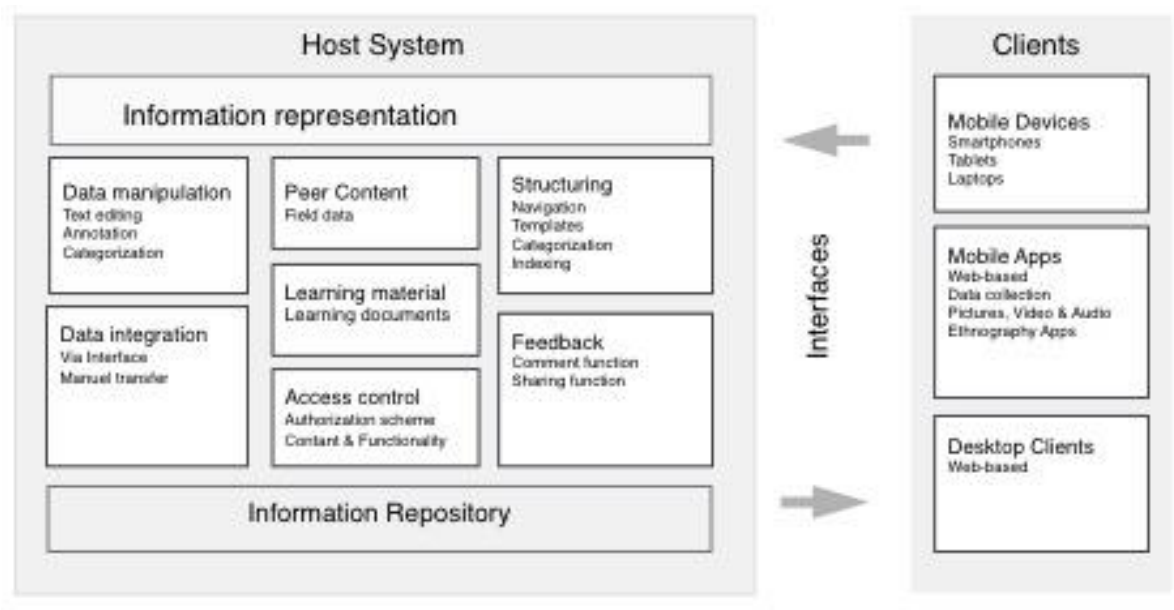

Figure 2. Functional design of D-Move Field Experience

As shown in Fig. 2 the technical implementation of the learning environment is based on a client-server architecture. The clients can be smartphones as well as desktop PCs using a standard web browser. Beside that, the integration of mobile applications for ethnographic research is implemented by software interfaces (Petrovic, 2009). Learners can upload text, 
pictures and videos from their field experiences directly from the clients into the learning environment at the host-system. This environment provides all necessary functions and data for the different clients and includes the main application logic, which allows the use of standard web-based clients.

\section{Evaluation of using the D-Move learning environment in comparison to traditional learning based on case studies}

D-Move as a sociotechnical environment to provide experience-based learning incorporates the modules D-Move Delphi and D-Move Field Experience. Both have been used by participants of a master class in information systems to teach certain course objectives as well as to evaluate the perceived differences to traditional learning in the classroom using case studies. The students of this master course, have been considered as digital natives, because of their age and their affinity to information. One group used the Delphi and the other one the Field Experience module. Both groups embraced 25 participants each with the same demographic characteristics. This Field Experience took about a semester and the interaction between the students and the teacher during the implementation of the Delphi has been online and during five course-meetings under the semester. The participants were asked to compare the use of D-Move with traditional learning in the classroom using case studies with regard to activation, emotion, satisfaction with the learning process, perceived learning success, and satisfaction with the learning environment. To measure those constructs well proofed items and scales were used together with a five stepped Likert scale. A one means that the attribute is perceived much better, a five means that it is perceived much inferior compared with a traditional learning environment based on case studies. The questions were answered anonymously using a web based questionnaire after finishing the course. The response rate in both groups was more than $98 \%$. 


\begin{tabular}{|c|c|c|c|c|c|c|}
\hline \multirow{2}{*}{ Construct } & \multirow{2}{*}{ Item } & \multicolumn{2}{|c|}{ Delphi } & \multicolumn{2}{|c|}{ Real World Insights } & \multirow{2}{*}{ Scale } \\
\hline & & $\alpha^{*}$ & $\mu^{* *}$ & $\alpha^{*}$ & $\mu^{* *}$ & \\
\hline Activation & Energetic activation & 0,8 & 1,3 & 0,84 & 1,7 & $\begin{array}{l}\text { Activation-Deactivation- } \\
\text { Check-List (AD-ACLS) } \\
\text { Imhof (1998) }\end{array}$ \\
\hline Emotion & $\begin{array}{l}\text { Interest } \\
\text { Surprise }\end{array}$ & 0,74 & $\begin{array}{l}2,19 \\
2,28\end{array}$ & $\begin{array}{l}0,58 \\
0,95\end{array}$ & $\begin{array}{l}2,0 \\
2,5\end{array}$ & $\begin{array}{l}\text { Differential Emotion } \\
\text { Scale, Merten and } \\
\text { Krause (1993) }\end{array}$ \\
\hline $\begin{array}{l}\text { Satisfaction with } \\
\text { the learning } \\
\text { process }\end{array}$ & $\begin{array}{l}\text { Free space } \\
\text { Personal judgment } \\
\text { Reflection } \\
\text { Personal initiative } \\
\text { Involvement }\end{array}$ & 0,87 & $\begin{array}{l}2,0 \\
1,7 \\
2,1 \\
1,6 \\
1,5\end{array}$ & 0,74 & $\begin{array}{l}1,7 \\
1,7 \\
1,6 \\
1,4 \\
1,6\end{array}$ & $\begin{array}{l}\text { Hoover and Whitehead } \\
\text { (1979) }\end{array}$ \\
\hline $\begin{array}{l}\text { Perceived learning } \\
\text { success }\end{array}$ & $\begin{array}{l}\text { Correlations } \\
\text { Practical application } \\
\text { Know How } \\
\text { New knowledge } \\
\text { Media competence }\end{array}$ & 0,81 & $\begin{array}{l}2,0 \\
2,0 \\
2,0 \\
1,9 \\
2,4\end{array}$ & 0,55 & $\begin{array}{l}2,1 \\
2,1 \\
2,4 \\
2,2 \\
1,7\end{array}$ & Likert (1932) \\
\hline $\begin{array}{l}\text { Satisfaction with } \\
\text { the learning } \\
\text { environment }\end{array}$ & $\begin{array}{l}\text { Sharing options } \\
\text { Location independence } \\
\text { Traceability } \\
\text { Usefulness } \\
\text { Transferability }\end{array}$ & 0,85 & $\begin{array}{l}1,9 \\
1,6 \\
2,3 \\
2,4 \\
2,2\end{array}$ & 0,78 & $\begin{array}{l}1,4 \\
1,7 \\
1,4 \\
1,4 \\
1,4\end{array}$ & Likert (1932) \\
\hline \multicolumn{7}{|c|}{$* a=$ Cronbach's Alpha } \\
\hline
\end{tabular}

Figure 4: Perceived differences after using the two D-Move components compared to traditional learning based on case studies (1.. much better, 5 .. much inferior)

In summary both components of the D-Move learning environment are perceived superior in all analyzed constructs to traditional learning in the classroom based on case studies. The strongest perceived advantages are activation, satisfaction with the learning process, and satisfaction with the learning environment. The improved activation can be attributed to the use of interactive digital media instead of traditional paper based methods (Petrovic, Edegger F., Kittl, Edegger B., 2008). That leads to a more ,lean forward' learning style (Kroeber-Riel \& Weinberg, 2003). It allows also more active search strategies within the digital universe for information about the learning topics as digital natives are familiar with. The strong support of communication within the own peer groups leads to more activation in the learning process as it allows bi-directional communication within the own network of peers. Furthermore, the confrontation with real world phenomena related to the learning topic which are selected, analyzed, and communicated by the learners themselves also increases the level of activation (Platzer \& Petrovic, 2011). Finally, participant's role as 
experts in the Delphi process increases own responsibility as well as recognition by others, both can lead to a higher degree of activation (Kolb, 1984). The very high amount of perceived superiority regarding activation is surprising as the D-Move learning environment was not compared to lectures in the classroom but to paper-based case study learning which incorporates a higher degree of activation than lectures.

The perceived superiority regarding satisfaction with learning process and learning environment can be attributed to the general design of D-Move. This is very close to the ,normal' every day environment of the students incorporating digital communication means like smartphones, blogs, search strategies in the world wide web, and communication with peers in an interactive way using text, pictures, and videos (Garret, 2010). As a consequence, learning is not any longer a dedicated activity which takes place in an environment perceived as artificially by learners (Siemens, 2005). Much more it will become part of the daily live. That conclusion does not mean that this kind of learning is superior to traditional lectures concerning all different learning objectives. But it can explain the high degree of satisfaction of learners with the process and environment.

\section{Limitations and further research questions}

A first limitation of the presented research is that the learners have been used the experience-based learning environment for the first time whereas they are familiar with learning based on case studies for many years. Some of the positive results regarding activation, satisfaction with the learning process, and satisfaction with the learning environment could be attributed to the pleasant surprise of innovation in learning environments. Further research should analyzed this effect by conducting repeated measurements within the same learners as part of a long-run study. Secondly, in further iterations of using D-Move a stronger focus should be on reasoning of the attitude and actual behavior of the digital natives utilizing this methodological advantages of the Delphi method as well as of the whole experienced based learning setting.

Further research could use D-Move for different learning objectives, not only comparing constructs perceived by the learners but also objective outcomes e.g. correct memorizing and understanding of certain facts. Finally, disregarding that the present learning environment is already much closer to the familiar daily life environment of digital natives than traditional learning setting, a closer integration to that daily life environment should be a next step in further development of D-Move. That means that the ability to select, capture, annotate, and share real world experiences as well as the participation on the Delphi should be integrated more seamlessly in the information and communication means already used by the learners. 


\section{References}

Friedl, J., \& Verčič, A. T. (2011). Media preferences of digital natives' internal communication: A pilot study. Public Relations Review, 37, 84-86.

Garrett, J. J. (2010): The Elements of User Experience: User-Centered Design for the Web and Beyond. Berkeley.

Ge, X./Huang, D./Zhang, H./Bowers, B. (2013): Three-Dimension Design for Mobile Learning: Pedagogical, Design, and Technological Considerations and Implications. In: Berge, L./Muilenburg, L. Y. (eds.): Handbook of Mobile Education. New York and Oxon.

Kittl, C., Edegger, F., \& Petrovic, O. (2009). Learning by Pervasive Gaming - An Empirical Study. In H. Ryu \& D. Parsons (Eds.), Innovative Mobile Learning Techniques and Technologies. New York.

Kolb, D. A. (1984): Experiential Learning: Experience as the Source of Learning and Development. Englewood Cliffs.

Kong, S. C., Chan, T.-W., Griffin, P., Hoppe, U., Huang, R., Kinshuk, ... Yu, S. (2014). Elearning in School Education in the Coming 10 Years for Developing 21st Century Skills: Critical Research Issues and Policy Implications. Journal of Educational Technology \& Society, 17, 70-78.

Kroeber-Riel, W./Weinberg, P. (2003): Konsumentenverhalten. 8. Auflage. Munich.

Petrovic, O. (2009): mGBL: Project Introduction. In: Petrovic, O./Brand, A. (eds.): Serious Games on the Move. Vienna.

Platzer, E., \& Petrovic, O. (2011). A learning environment for developers of mobile apps. In 2011 IEEE Global Engineering Education Conference, EDUCON 2011 (pp. 14-19).

Purcell, K., Rainie, L., Heaps, A., Buchanan, J., Friedrich, L., Jacklin, A., Zickuhr, K. (2012). How Teens Do Research in the Digital World. Washington DC.

Siemens, G. (2005). Connectivism: A learning theory for the Digital Age. International Journal of Instructional Technology and Distance Learning, 2, 1-8.

Thompson, P. (2013). The digital natives as learners: Technology use patterns and approaches to learning. Computers \& Education, 65, 12-33. 